\title{
The Necessity of Intentionally Closed Spaces for LGBTQ Youth of Color
}

\author{
Krishna Pattisapu, Ph.D., University of Colorado Boulder
}

Krishna is a queer brown cisgender woman and critical educator who works as Director of Diversity Recruitment and Retention for the School of Education at the University of Colorado Boulder. She supports first-generation students, students of color, and LGBTQ students. Originally from the rural Midwest, Krishna is a leader in local LGBTQ organizing and intersectional social justice efforts.

\section{Summary}

In this Dialogues essay, I argue that intentionally closed spaces provide important opportunities for LGBTQ youth of color to reflect on their experiences with racism without fear of judgement and without the expectation to educate white queer allies. Intentionally closed spaces are not antithetical to alliances and cooperative efforts; these spaces make it possible for LGBTQ youth of color to process shared experiences with exclusion, oppression, and trauma so that we can enter intersectional alliances feeling healed and more energized. The arguments I present here may be of interest to community leaders, K-12 and university educators, and students who are involved in the establishment and maintenance of spaces that support LGBTQ youth of color.

Keywords: QTPOC, intersectionality, diversity and inclusion, intentionally closed spaces, whiteness

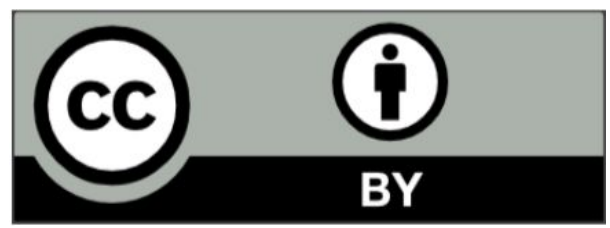

See: $\underline{\text { creativecommons.org/licenses/by/4.0 }}$ 


\title{
The Necessity of Intentionally Closed Spaces for LGBTQ Youth of Color
}

\author{
Krishna Pattisapu, Ph.D., University of Colorado Boulder
}

The first time I encountered a protected space for LGBTQ people of color, I was an undergraduate student attending a conference for LGBTQ college students, higher education professionals, and community activists in the U.S. Midwest. That year, the student organizers of the conference announced that an entire series of workshops would be open only to conference-goers who identify as LGBTQ people of color. This "QTPOC" (queer and trans people of color) workshop series followed the precedent set in the previous year, when organizers developed a track of workshops that were open only to transgender people. The organizers based their decisions to establish these series on the lack of available spaces where transgender people could talk about their experiences navigating transphobia and cis privilege, and where queer and transgender people of color could unpack the weight of racism and whiteness, free from the voyeuristic and scrutinizing gazes of cisgender and white folks.

The organizers' decision to create these restricted tracks sparked nothing short of controversy and outrage from white LGBTQ attendees, as well as from some attendees of color. Those who opposed the idea hurled accusations that it bred a climate of segregation and intolerance that fragmented the conference community. I, too, felt skeptical of the idea at firstuntil I attended my first QTPOC workshop. Never before had I experienced the feeling of being seen and respected on the basis of all of my identities, no longer forced to choose between spaces that nurtured my queer identity or my brown identity. In that space, I had the opportunity to learn alongside other LGBTQ people of color without the need to engage in the emotional labor of educating white people in the room about our experiences (or worse yet, of needing to provide enough supporting evidence for white people to believe us when we discussed our experiences navigating racism and whiteness in queer spaces). It was the first time I felt collectively seen and held in my queer brown body.

Since that experience, I have believed in the importance of establishing and nurturing what I refer to as intentionally closed spaces. I have fought hard for these spaces to exist, often at the expense of being labeled as a divisive segregationist who threatens collaborations and alliances. Intentionally closed spaces and those who support them are often criticized as standing in direct opposition to efforts for diversity and inclusivity. It is, in fact because of the failures of mainstream spaces to be authentically diverse and inclusive that intentionally closed spaces are necessary. For example, because mainstream spaces have so often failed to fully and meaningfully include LGBTQ people, intentionally closed spaces for LGBTQ people have emerged to recognize, celebrate, and support LGBTQ people. Similarly, because LGBTQ spaces frequently fail to challenge racism and denounce transphobia, closed spaces for LGBTQ people of color and transgender people must exist. By cultivating spaces of our own, we can resist 
replicating the racist, transphobic, and homophobic foundations that underpin so many existing spaces.

For three years I volunteered with Wellspring, a recently-shuttered LGBTQ youth group in the community where I live. This intentionally closed group made rare exceptions, allowing only the most devoted straight and cisgender allies to attend. Each week, a group of nearly twenty middle school and high school students who identify across spectrums as lesbian, gay, bisexual, pansexual, transgender, nonbinary, queer, and questioning showed up to build community, learn buried LGBTQ histories, consume LGBTQ media, and rally for social change in their schools, families, and places of worship. Far more often the victims of bullying than their straight and cisgender peers, these young people came together each week for the opportunity to share, process, and heal from the violence, trauma, and exclusion they face daily. There, they felt no pressure to argue the legitimacy of their gender identities or sexual orientations. Adult volunteers - all of whom also identify as LGBTQ — were there to support them. It was, as its name suggested, an oasis, a safer space away from the norm.

Even for supporters, intentionally closed spaces can present considerable challenges, particularly for individuals who experience marginalization on the basis of more than one of their social identities. Of the group of twenty youth that gathered weekly at Wellspring, only a few identify as people of color. Although the leaders and volunteers of Wellspring made efforts to engage youth in conversations about race and racism, the space maintained and reiterated whiteness. Youth of color who came to the space reported feeling misunderstood, judged, and invisible. Wellspring welcomed them on the basis of gender and sexuality, but more often than not failed to account for their identities as queer youth of color. Unless intentionally closed LGBTQ spaces are deliberately anti-racist, they risk reproducing the same racism present in culture at large. Furthermore, a critical understanding of the cultural underrepresentation and oppression of LGBTQ people does not automatically facilitate racial awareness and accountability to be actively anti-racist. These are values and skills that must be constantly practiced, critically examined, and improved.

As Wellspring's tenure in our community drew to a close, LGBTQ leaders advocated for the creation of another intentionally closed space for LGBTQ youth, as well as for the creation of a space for LGBTQ youth of color only. With this announcement, I witnessed reactions similar to those I heard at the conference I attended as an undergraduate student. Leaders were accused of fragmenting the youth population, of creating unnecessary divisions, and preventing collaboration. Supporters like me argued that intentionally closed spaces for LGBTQ people of color are overwhelmingly necessary in a community where over $84 \%$ of residents are white. A dedicated space where LGBTQ youth of color, who experience an onslaught of microaggressions every day, can connect with one another beyond the far-reaching grasps of homophobia, transphobia, and racism can be healing and transformative. This is not to say that spaces for LGBTQ people of color are immune to reproducing discrimination. Unexamined privileges and biases around ableism, transphobia, Islamophobia, anti-blackness, and distrust of white-passing 
people of color (just to name a few) can and do affect these spaces. What I know is this: while intentionally closed spaces for LGBTQ people of color are not perfect, they are necessary.

Most importantly, intentionally closed spaces do not exist in opposition to alliances across identities. In fact, it is the establishment and nurturing of intentionally closed spaces that make meaningful alliances possible. When people of color, LGBTQ people, people with disabilities, and people who face age discrimination are able to access spaces where they can heal one another without the fear of judgement or additional discrimination, we can emerge feeling energized, resilient, self-aware, and ready to move toward collective liberation. Intentionally closed spaces are not ideologically separate from collaboration; they are an important part of the process of building intersectional alliances. Protecting intentionally closed spaces for LGBTQ youth of color is an important move toward rectifying legacies of racism in the LGBTQ community, and toward supporting LGBTQ young people on the basis of all of their identities.

\section{Author Note}

Krishna Pattisapu, Ph.D., is Director of Diversity Recruitment and Retention for the School of Education at the University of Colorado Boulder.

Krishna currently serves as Vice President for the Board of Directors at Out Boulder County, an LGBTQ advocacy organization in Boulder, Colorado.

Correspondence regarding this article should be sent to Krishna.Pattisapu@Colorado.edu 


\section{References}

Balsam, K.F., Molina, Y., Beadnell, B., Simoni, J., \& Walters, K. (2017). Measuring multiple minority stress: the LGBT people of color microaggressions scale. Cultural Diversity and Ethnic Minority Psychology, 17, 163-174. https://psycnet.apa.org/record/2011-10497-005

Blackwell, K. (2018). Why people of color need spaces without white people. Arrow Journal Online:

https://arrow-journal.org/why-people-of-color-need-spaces-without-white-people/

Cochran, G. (2018). "The Problem with Diversity, Inclusion, and Equity." Scholarly Kitchen. 22 June 2018.

https://scholarlykitchen.sspnet.org/2018/06/22/problem-diversity-inclusion-equity/

Mayo, C. (2014). LGBTQ youth and education: Policies and practices. J.A. Banks (Ed.). New York, NY: Teachers College Press.

Flores, A.R. (2017). Yes, there's racism in the LGBT community. But there's more outside of it. The Washington Post. https://www.washingtonpost.com/news/monkey-cage/wp/2017/07/07/yes-there-is-racism -in-the-lgbtq-community-but-not-as-much-as-outside-it/

Fox, C.O., \& Ore, T.E.. (2010). Uncovering normalized gender and race subjectivities in LGBT "safe spaces." Feminist Studies, 36, 629-649.

GLSEN LGBTQ student statistics: https://www.glsen.org/learn/research/national

McKenzie, M. \& Balasubramanian, J. (2013). QTPOC Chat 4: Racism within QTPOC community. Black Girl Dangerous: https://www.bgdblog.org/2013/07/2013724qtpoc-chat-4-racism-within-qtpoc-community I

Ramsawakh, M. (2017). Why LGBT spaces can be uncomfortable for queer people of colour. The body is not an apology: Radical self-love for everybody and every body. https://thebodyisnotanapology.com/magazine/why-lgbt-spaces-can-be-uncomfortable-for -queer-people-of-colour/

Serano, Julia. (2018). Julia's trans, gender, sexuality, and activism glossary. http://www.juliaserano.com/terminology.html

YW Boston Blog (2017). What is intersectionality, and what does it have to do with me? https://www.ywboston.org/2017/03/what-is-intersectionality-and-what-does-it-have-to-do -with-me/ 